\title{
MiR-495-3p facilitates colon cancer cell proliferation via Wnt/B-catenin signaling pathway by restraining Wnt inhibitory factor
}

\author{
Lin Lin ${ }^{1,2}$, Gangling Tong ${ }^{3}$, Meixiang $\mathrm{Li}^{2}$, Aixue Liu $^{2}$ and Senming Wang ${ }^{1 *}$ \\ ${ }_{1}^{1}$ Department of Oncology, Zhujiang Hospital, Southern Medical University, 253 Middle Industrial Avenue, Guangzhou, China, \\ ${ }^{2}$ Department of Oncology, Shenzhen Second People's Hospital, ${ }^{3}$ Department of Oncology, Peking University Shenzhen \\ Hospital, Shenzhen 518036, Guangdong, PR China
}

*For correspondence: Email: 13902404566@126.com

\begin{abstract}
Purpose: To demonstrate whether miR-495-3p promote the occurrence of colon cancer and development of colon cancer stem cells by inhibiting Wnt inhibitory factor (WIF1).

Methods: The level of MiRNA and mRNA in cells were tested by real-time polymerase chain reaction (RT-PCR). Cell viability was assessed by 3-(4,5-dimethyl-2-thiazolyl)-2,5-diphenyl-2-H-tetrazolium bromide (MTT) assay. Cell spheroid formation was measured by colony assay. Expression protein was tested using Western blotting. $\beta$-catenin binding ability was detected by chromatin immunoprecipitation (ChIP) assay. MiRNA target gene was defined by luciferase assay.

Results: Compared with normal colon cells and tissue, miR-495-3p is elevated in colon cancer cells and tissues, which regulate proliferation, level of stemness factors SOX-9, Bmil, and OCT-4 in HCT-116 cells, even spheroid formation. Overexpression of miR-495-3p inhibits the expression of WIF1 in HCT116 cells and promotes colon tumorigenesis by binding with 3'-UTR. MiR-495-3p inhibitor downregulated WIF1-enhanced sphere formation of colon cancer cells.

Conclusion: These results indicate that miR-495-3p/WIF1 can modulate the development of colon cancer and is a potential target for prevention and treatment of cancer.
\end{abstract}

Keywords: MiR-495-3p, Wnt inhibitory factor, Colon cancer, Stemness, Tumorigenesis

\begin{abstract}
Tropical Journal of Pharmaceutical Research is indexed by Science Citation Index (SciSearch), Scopus, International Pharmaceutical Abstract, Chemical Abstracts, Embase, Index Copernicus, EBSCO, African Index Medicus, JournalSeek, Journal Citation Reports/Science Edition, Directory of Open Access Journals (DOAJ), African Journal Online, Bioline International, Open-J-Gate and Pharmacy Abstracts
\end{abstract}

\section{INTRODUCTION}

Colorectal cancer is a heavy burden around the world that accounts for more than 1 million newly diagnosed cases and more than six hundred thousand patients die of every year [1]. However, its incidence has declined in a number of Western countries, mainly because of early detection, prevention, and treatment measures [2]. Therefore, the underlying etiologies impacting colon cancer tumorigenesis has to be classified to help in monitoring the progress of therapy. At present, molecular targets have been investigated in the treatment of many types of cancer. MicroRNAs (miRNAs) are proposed to be prospective candidates for cancer therapy. MiRNAs are small RNAs comprising of of 20-25 nucleotides, which cannot code for protein but regulate expression of gene through reacting with mRNAs. By complementary binding to the 3'-UTR of target mRNAs, miRNAs either suppress mRNAs translation or degrade them directly [3]. MiR-495 was previously considered to be a breast cancer cell promoter that targeted the regulation of E-cadherin and REDD1 [4]. This miRNA was also observed to be decreased in 
MLL-rearranged leukemia [5] and in gastric cancer cells where it is a suppressor of phosphatase of regenerating liver-3 (PRL-3) [6]. PRL-3 gene is closely related to gastric cancer metastasis, and is proposed to play an initating role by facilitating cancer cell migration and invasion. MiR-495 was also previously reported to shift the metabolic mode in glioma cells through targeting Glut1 [7]. Wang observed that miR-495 could regulate Bmi-1 to arrest the $\mathrm{G} 1$ to $S$ phase transition in breast cancer [8]. Very recently, miR-495 was found to participate in Wnt signaling pathway regulation in cardiomyocyte proliferation [9], whose main function is to promote cell proliferation and differentiation $[10,11]$. However, little else is known about the reverse chain of miR-495, miR-495-3p, the implications of its function and expression in colon cancer.

It was observed in this study that miR-495-3p is elevated in colon cancer cell compared to control group both at tissue and cellular levels. MiR-495$3 p$ promoted colon cancer cell growth and tumorigenesis in vitro. We also revealed that Wnt inhibitory factor 1 (WIF1) is the direct target of miR-495-3p. MiR-495-3p is a potential therapeutic target worth further investigation in colon cancer treatment.

\section{EXPERIMENTAL}

\section{Tissue collection and RNA extraction}

The tissue samples used in this study were collected from Shenzhen Second People's Hospital colon cancer patients. Trizol standard method was adopted to extract the total RNA. This study was approved by Institutional Ethics Board (IRB) of Shenzhen Second People's Hospital.

\section{Construction of plasmids}

Human miR-495-3p promoter was produced by PCR and cloned into the pGL3-basic-luciferase reporter plasmid (Promega, Madison, WI). In order to construct the pGL3-control luciferase vector, the full-length of the 3'-UTR of WIF1 was subcloned into pEGFP-C3. Te synthetic RNAi was cloned into the pSuper-retropuro plasmid (Oligoengine, WA) to block endogenous WIF1 expression. miR-495-3p inhibitor and mimics were bought from RiboBio (Guangzhou, China).

\section{Cell culture and transfection}

CCD18Co, DIFI, HCT-8, SW620, Caco-2, SW480, and HCT-116 cell lines were obtained from American Type Culture Collection (ATCC,
USA) and maintained in DMEM containing $10 \%$ fetal calf serum (Hyclone) in an incubator at $5 \%$ $\mathrm{CO}_{2}$ and $37{ }^{\circ} \mathrm{C}$. The cells were transient transfected by miR-495-3p inhibitor or mimics, and siRNA-WIF1 using lipofectamine 2000 (ThermoFisher) according to the manual.

\section{MTT assay}

HCT-116 cells were planted in 96-well plate at 2 $\times 10^{3}$ cells/well and cultured. Then, miR-495-3p inhibitor or mimics were transfected in cells for $24 \mathrm{~h}$. Twenty hours later, $50 \mu \mathrm{g}$ MTT (Sigma, MO) was added in each well. After $4 \mathrm{~h}, 100 \mu \mathrm{L}$ DMSO was dropped $i-n$ each well to dissolve the formazan and the optical density at $450 \mathrm{~nm}$ was measured on a microplate reader (Bio-tek, USA).

\section{Spheroid formation assay}

HCT-116 cells were planted at density of 500 cells/well in six well ultra-low cluster plate and maintained in DMEM / F12 medium supplemented with B27 at 1:50 (Invitrogen), bovine serum albumin at $0.4 \%$ (Sigma), EGF at $20 \mathrm{ng} / \mathrm{mL}$ (BD Biosciences), and insulin at 4 $\mathrm{mg} / \mathrm{mL}$ (Sigma) for 2 weeks. The number of spherical, tight, and non-adherent masses with diameter $>50 \mu \mathrm{m}$ of HCT-116 cell spheres was counted under an inverted microscope. Efficiency of sphere formation (S) was computed as in Eq 1.

$\mathrm{S}(\%)=(\mathrm{C} / \mathrm{L}) 100$

where $C$ and $L$ are colonies and input cells, respectively.

\section{Luciferase assay}

Luciferase reporter plasmids and miRNAs were co-transfected into HCT-116 cells. After 2 days, the luciferase activity was tested upon a luciferase assay kit (Promega, Madison, WI). Each experiment was repeated three times.

\section{TOP/FOP detection}

TOPglow/FOPglow TCF reporter kit (Millipore) was used for the detection of Wnt signaling pathway activity. HCT-116 cells were transfected with TOPglow and FOPglow according to the manual. Each test was repeated at least 3 times.

\section{Chromatin immunoprecipitation}

ChIP assay was done as previously described [12]. In brief, HCT-116 cells were cross-linked with $1 \%$ formaldehyde for 10 minutes and then incubated with $125 \mathrm{mM}$ glycine. After 
centrifugation, the nuclei were separated and the precipitation was suspended by lysis buffer, then sonicated to obtain 200 to 600 bp DNA fragment. Using an antibody against $\beta$-catenin, immunoprecipitation was performed with protein $G$ magnetic beads. In addition, IgG was treated as negative control. Real-time PCR was applied with tiled primers to validate the enrichment.

\section{Real-time PCR}

RNase-free water (Promega) dissolved RNA was used to analyze gene expression according to the real-time PCR standard method. $2^{-} \Delta \Delta^{\mathrm{Ct}}$ method was used to calculate changes in gene expression with an internal control of $18 \mathrm{~S}$ rRNA.

\section{Western blot}

After different treatments for an indicated time, cells were washed in cold PBS and lysed with loading buffer for 30-60 min on ice. The samples were loaded on SDS-PAGE, and then transferred to polyvinylidene fluoride (PVDF) membrane. Next, the membrane was blocked in 5\% nonfat milk and probed with different primary antibodies. Then the membranes were incubated in horse radish peroxidase (HRP)-conjugated secondary antibodies at $24{ }^{\circ} \mathrm{C}$ for $60 \mathrm{~min}$. Finally, enhanced chemiluminescence (Thermo Fisher Scientific, UK) were used to detecting the binding signals.

\section{Statistical analysis}

All data analyses were adopted on SPSS software 16.0. The data are depicted as mean \pm standard deviation (SD). Two-tailed one-way ANOVA or two-tailed Student's t-test was used for data comparison. Correlation between miR495-3p and WIF1 expressions in the specimens was analyzed by Spearman rank correlation test. $P<0.05$ was set as statistical significant.

\section{RESULTS}

\section{MiR-495-3p increased in colon cancer cell lines and tissues}

To investigate miR-495-3p expression in human colon cancer, we searched TCGA database and compared miR-495-3p expression in 85 human colon cancer tissues and 33 normal colon tissues. Further, the content of miR-495-3p in colon cancer tissues was significantly upregulated compared with control $(p<0.05$, Figure 1A). Moreover, it was found that miR-495$3 p$ levels were obviously increased compared with normal colon cell line CCD18Co in 6 colon cancer cell lines ( $p<0.05$, Figure 1B). Next, 10 paired our hospital colon cancer and corresponding para-carcinoma tissues were detected by real-time PCR. It was observed that miR-495-3p level in colon cancer tissues was obviously increased compare to normal tissues, which indicated its elevation in colorectal cancer $(p<0.05$, Figure 1C).

\section{MiR-495-3p facilitated proliferation and spheroid formation of HCT-116 cell}

As miR-495-3p was upregulated in colon cancer, miR-495-3p may involve in facilitating colon cancer proliferation. It was showed that expression of MiR-495-3p was changed by miR495-3p mimics as well as inhibitor transfection (Figure 2A, Figure 2B). Next, MTT assay demonstrated that miR-495-3p mimics elevated, whereas miR-495-3p inhibitor significantly declined HCT-116 cell viability after $96 \mathrm{~h}$ treatment (Figure 2C). As shown in Figure 2B compared with control group, miR-495-3p simulations significantly enhanced the spheres formation, whereas the miR-495-3p inhibitor reduced the number of spheres. It indicates that miR-495-3p may affect HCT-116 cell viability and spheroid formation.

\section{MiR-495-3p promoted Wnt signaling pathway}

Previous studies revealed that Wnt signaling pathway may be involved in colon cancer cell proliferation and stemness, thus we speculated that miR-495-3p may achieve its impact on colon cancer cells via Wnt signaling pathway. TOP/FOP ratio was considerably elevated in HCT-116 cells when miR-495-3p was upregulated, while it reduced in cells with miR$495-3 p$-in transfection ( $p<0.05$, Figure 3A). We further assessed the influence of miR-495-3p on $\beta$-catenin nuclear translocation. After its extraction from the cytoplasm and the nucleus, the levels of various proteins were measured using western blotting. It was shown that content of $\beta$-catenin in the nucleus was markedly increased in the miR-495-3p group ( $p<0.05$, Figure 3B). Furthermore, real time PCR showed that various target genes were increased by miR495-3p and downregulated by inhibitor of miR495-3p ( $p<0.05$, Figure 3C). Moreover, ChIP assay was applied to evaluate the activity of Wnt signaling pathway. It was found that the upregulated miR-495-3p promoted nuclear $\beta$ catenin binding with the promoter of MMP-9 and RUNX2, enhancing gene transcription and help colon cancer cell proliferation $(p<0.05$, Figure 3D). Furthermore, genes related with stemness were upregulated in HCT-116 cells with transfection of miR-495-3p, such as SOX-9, OCT-4, and Klf4, ( $p<0.05$, Figure 3E). 
A

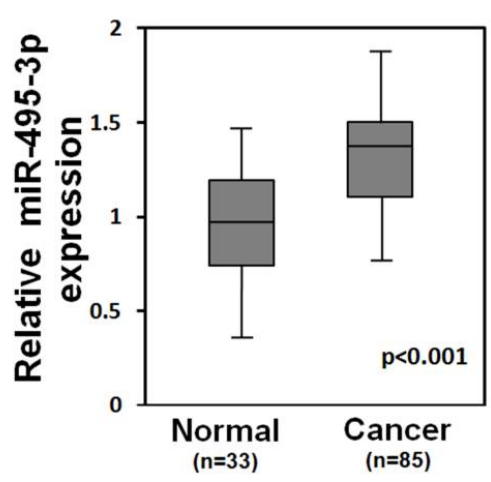

B

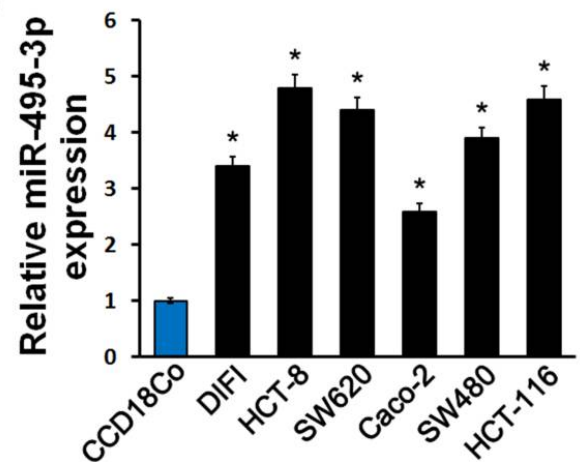

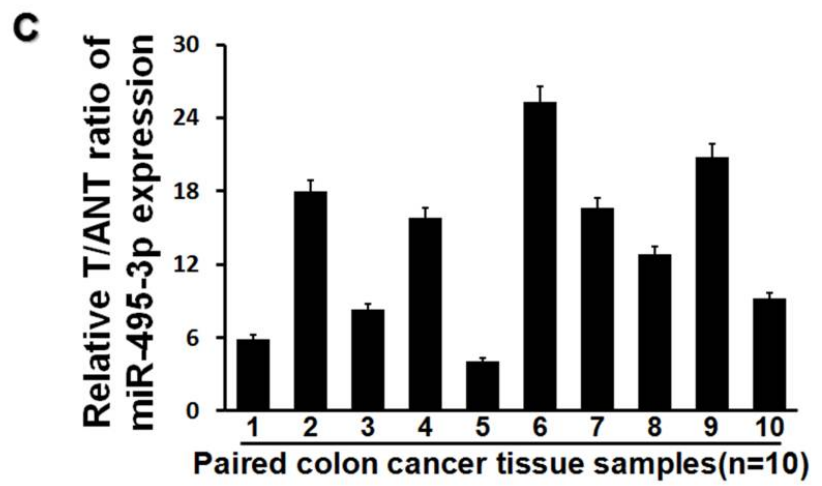

Figure 1: MiR-495-3p level increased in colon cancer cells and tissues. A = MiR-495-3p level in TCGA database; $B=$ Expression of MiR-495-3p in colon cancer and normal colon cells; C; MiR-495-3p level in paired colon cancer and adjacent normal tissues; ${ }^{*} p<0.05$

A

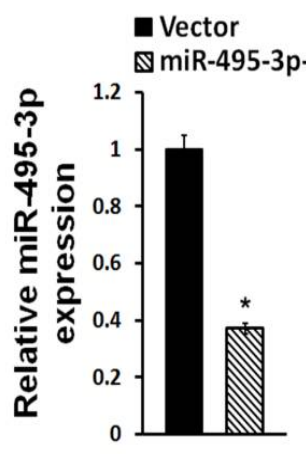

C

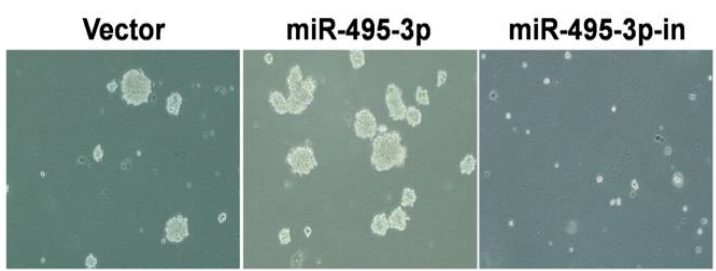

B

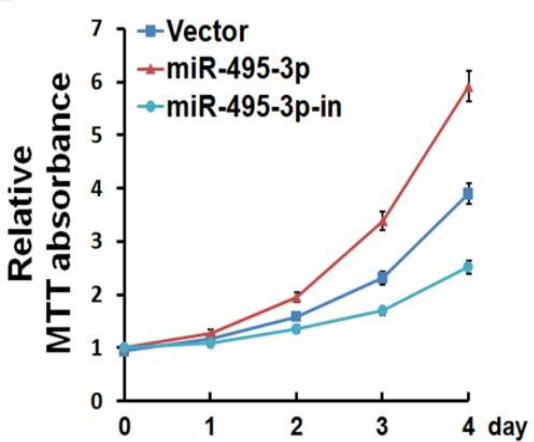

Q Vector

QmiR-495-3p

$\square \mathrm{miR}-495-3 p$-in

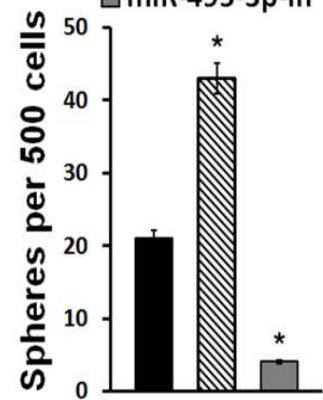

Figure 2. MiR-495-3p promoted proliferation and spheroid formation of HCT-116 cell. $A=$ MiR-495-3p level in HTC-116 cells after transfection of miR-495-3p simulations or inhibitor; $B=$ Cell viability of HCT-116 with treatment of miR-495-3p mimics or transfection of inhibitor; $\mathrm{C}=$ Cell tumorigenesis ability of HCT-116 evaluated by spheroid formation assay after treatment with miR-495-3p simulations or inhibitor; ${ }^{*} p<0.05$ 


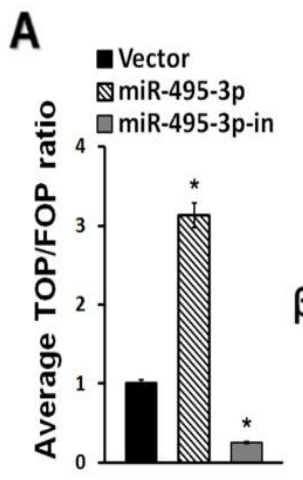

B

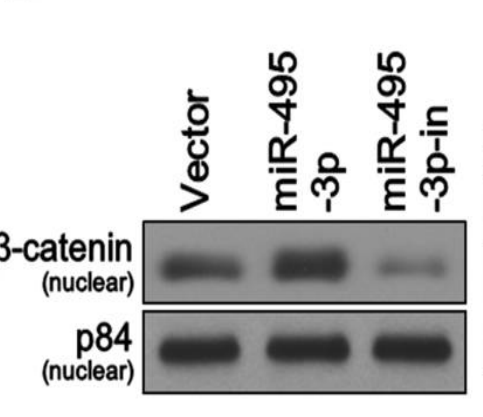

D

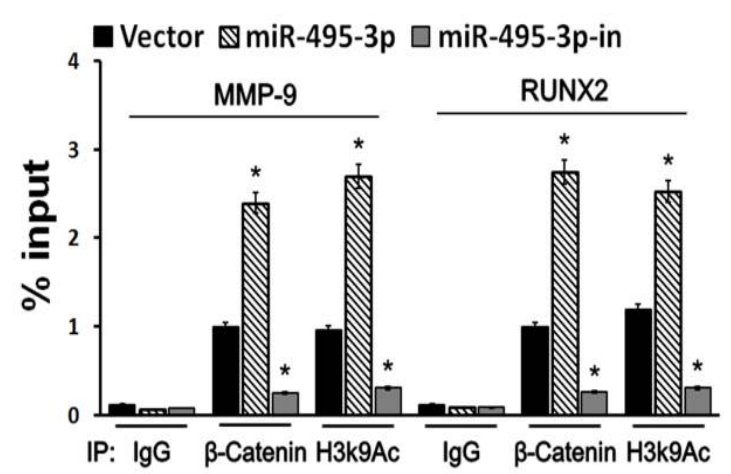

E

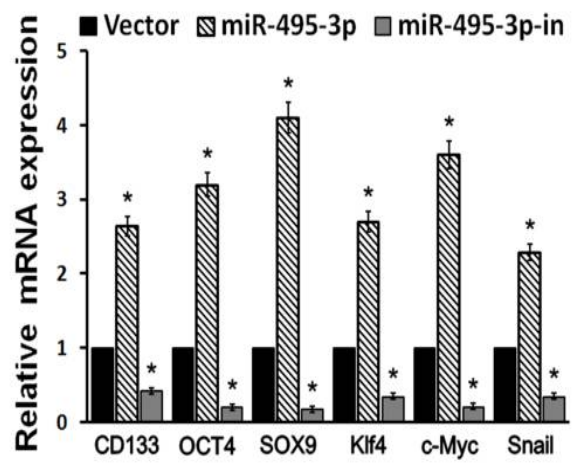

Figure 3: MiR-495-3p promoted Wnt signaling pathway. $A=$ Wnt signaling pathway activity was determinates by TOP/FOP ratio; $B=$ Nuclear level of $\beta$-catenin was detected by western blotting; $C=$ Expressions of cyclin D1, OCN, and ALP mRNA were detected by real-time PCR. D = MMP-9 and RUNX2 were detected by ChIP. E. Cell stemness related mRNA expressions were detected using real-time PCR, ${ }^{*} p<0.05$

\section{MiR-495-3p targeting WIF1 during spheroid formation}

Upon checking the miRNA database, it was suggesting that miR-495-3p may bind with WIF1 mRNA based on complementary pairing (Figure 4A). After Luciferase assay, it was demonstrating that miR-495-3p dose-dependently reduced the luciferase intensity of WIF1 3'-UTR, while there was no significant impact on WIF1 3'-UTR mutation (Figure 4B, Figure 4C). In contrast, the knockdown WIF1 would enhance the spheroid formation of HCT-116 cells though decreasing miR-495-3p inhibitor $(p<0.05$, Figure 4D). Concurrently, it was negatively correlated between WIF1 level and miR-495-3p, also indicating this reaction (Figure 4E).

\section{DISCUSSION}

Several studies have exhibited the influence of miRNAs in colon cancer tumorigenesis, including miR-145 [13], let-7 [14], miR-320b [15]. These observations focus attention on miRNA based treatment for colon cancer $[16,17]$.
By searching TCGA database, we observed that miR-495-3p expression was enhanced in colon tumor specimens than in the control. A similar result was also observed in 6 colon cancer cell lines compared with CCD18Co. Therefore, we proposed that miR-495-3p may participate in human colon cancer oncogenesis. The influence of miR-495-3p upregulation and miR-495-3p inhibition were further assessed using MTT assay and spheroid formation assay. The result indicates that miR-495-3p overexpression increased growth and spheroid formation. On the contrary, miR-495-3p suppression results in weaker cell viability and spheroid formation. These results agreed with the opinion that miR$495-3 p$ regulates cell proliferation in colon cancer cells.

The potential targets of miR-495-3p was further identified in miRanda databases to, which was further tested by luciferase assay. The results indicate that miR-495-3p directly obstructs WIF1 mRNA translation into protein. 
A

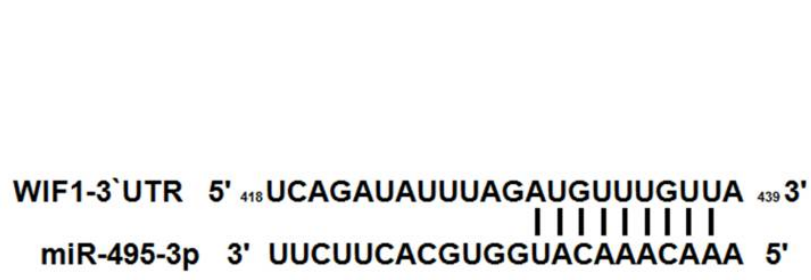

WIF1-3'UTR-mut $\mathbf{5}^{\prime}{ }_{48}$ UCAGAUAUUUAGAUGUUUCAAA ${ }_{439} 3^{\prime}$

C

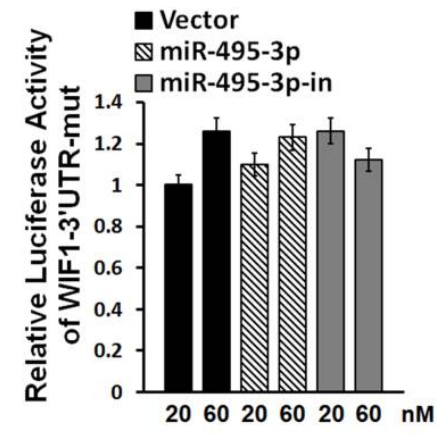

B

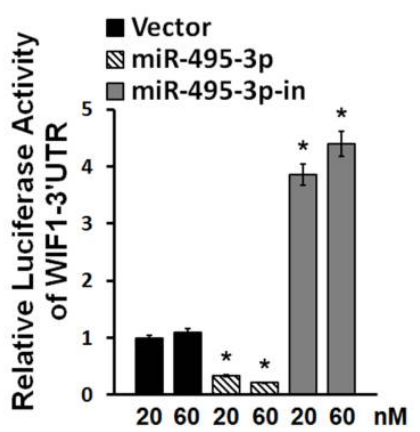

E

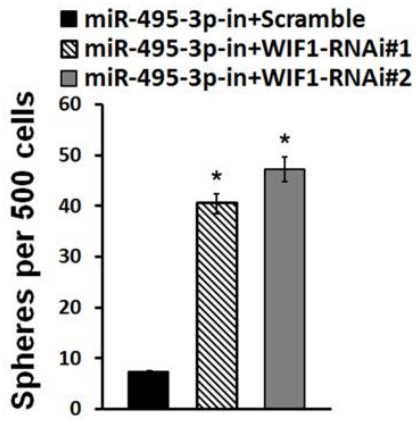

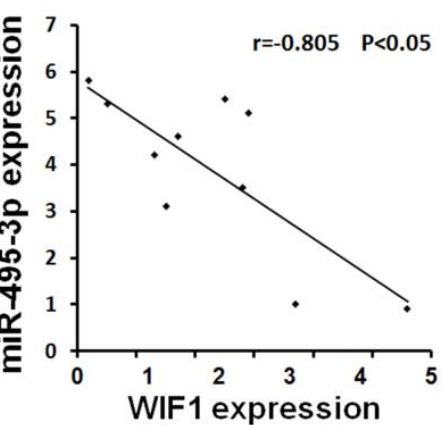

Figure 4: MiR-495-3p targeting WIF1 during spheroid formation, the cells were transfected with WIF1-3' UTRmutation reporter together with miR-495-3p mimics or inhibitor. $A=$ miR-495-3p targeting the 3' UTR of WIF1; $B$. Dual-luciferase reporter assay of the WIF1-3' UTR in HCT-116 cells; $\mathrm{C}=$ Dual-luciferase reporter assay detection of WIF1-3' UTR-mutation in HCT-116 cells; D = Spheroid formation assay of HCT-116 cell for testing tumorigenesis ability after WIF1 knockdown together with miR-495-3p inhibitor transfection; $\mathrm{E}=$ Correlation analysis of miR-495-3p and WIF1 mRNA in colon cancer tissues; ${ }^{*} p<0.05$

To explore whether WIF1 regulates colon cancer cell tumorigenesis, we performed WIF1 knockdown and studied spheroid formation in vitro. Cell spheroid formation decreased by miR495-3p inhibition was apparently enhanced by WIF1 downregulation. Furthermore, Pearson correlation analysis of miR-495-3p and WIF1 expression in colon cancer patients exhibited a negative correlation. WIF1 is a lipid-binding protein that combines with Wnt protein to prevent the activation of $\mathrm{Wnt} / \beta$-catenin pathway [18]. At present, WIF1 gene expression is dysregulated in the peripheral blood of human colon cancer and could be treated as a promising marker [19]. In accord with previous reports, we observed that WIF1 may participate in colon cancer cell viability and growth.

Wnt/ß-catenin signaling pathway plays a key role in promoting the progress of colon cancer [20] and is thought to be extremely important in tumorigenesis [21]. This pathway affects several biological behaviors, including proliferation, invasion, angiogenesis, migration, and apoptosis [22-24]. Abnormal expression of molecules within $W n t / \beta$-catenin signaling is proposed to participate in the progress of colon cancer. $\mathrm{Wnt} / \beta$-catenin signaling can be restrained by multiple factors through bindingto the Wnt ligand or receptors, including Frizzled related proteins (sFRPs), WIF1, and CTNNBIP1 [25]. Our results showed that WIF1 is suppressed by miR-495-3p in colon cancer cells and tissues, leading to Wnt signaling aberrant activation. Also, miR-495-3p overexpression facilitated the activation of stemness markers, such as SOX9, CD133, and KIf4.

Since we found that WIF1 is regulated by miR495-3p and former studies reported that it affects $W n t / \beta$-catenin signaling, we explored the impact of miR-495-3p on the ratio of TOP/FOP and $\beta$ catenin nuclear translocation. We discovered that miR-495-3p upregulation accelerated $\beta$-catenin nuclear translocation and elevated TOP/FOP ratio, which further confirms the character of miR-495-3p in mediating $W n t / \beta$-catenin signaling pathway. Multiple growth-promoting genes were activated by $\mathrm{Wnt} / \beta$-catenin signaling at the transcription level, such as cyclin D1, OCN, ALP, MMP-9, and RUNX2 [26-29]. We observed that the levels of cyclin D1, OCN, and ALP were markedly enhanced by miR-495-3p mimics and inhibited by miR-495-3p inhibitor. Meanwhile, the combining capacity of $\beta$-catenin with the promoter of MMP-9 and RUNX2 was enhanced after miR-495-3p upregulation. 


\section{CONCLUSION}

MiR-495-3p is elevated in colon cancer. This oncogene is a negative controller of $\mathrm{Wnt} / \mathrm{B}$ catenin signaling inhibitor, and abnormal activation of miR-495-3p in colon cancer enhances $W n t / \beta$-catenin signaling pathway. This aberrant signaling further facilitates cells to accelerate spheroid formation and stemness, leading to colon cell proliferation and tumorigenesis. The results in this study provide a new insight into colon cancer pathogenesis and a potential direction for colon cancer therapy, as miR-495-3p activity affects colon cancer progression.

\section{DECLARATIONS}

\section{Acknowledgement}

This study was supported by institutional departmental funding.

\section{Conflict of Interest}

No conflict of interest associated with this work.

\section{Contribution of Authors}

The authors declare that this work was done by the authors named in this article and all liabilities pertaining to claims relating to the content of this article will be borne by them.

\section{Open Access}

This is an Open Access article that uses a funding model which does not charge readers or their institutions for access and distributed under the terms of the Creative Commons Attribution License (http://creativecommons.org/licenses/by/ 4.0) and the Budapest Open Access Initiative (http://www.budapestopenaccessinitiative.org/rea d), which permit unrestricted use, distribution, and reproduction in any medium, provided the original work is properly credited.

\section{REFERENCES}

1. Jemal A, Bray F, Center MM, Ferlay J, Ward E, Forman D. Global cancer statistics. CA Cancer J Clin 2011; 61: 69-90.

2. Bartel DP. MicroRNAs: target recognition and regulatory functions. Cell 2009; 136: 215-233.

3. Lai EC. Micro RNAs are complementary to 3' UTR sequence motifs that mediate negative posttranscriptional regulation. Nat Genet 2002; 30: 363-364.
4. Hwang-Verslues WW, Chang $P H$, Wei $P C$, Yang $C Y$, Huang CK, Kuo WH, Shew JY, Chang KJ, Lee EY, Lee WH. miR-495 is upregulated by E12/E47 in breast cancer stem cells, and promotes oncogenesis and hypoxia resistance via downregulation of E-cadherin and REDD1. Oncogene 2011; 30: 2463-2474.

5. Jiang $X$, Huang $H, L i Z, H e C, L i Y$, Chen P, Gurbuxani S, Arnovitz $S$, Hong GM, Price $C$, et al. MiR-495 is a tumorsuppressor microRNA down-regulated in MLLrearranged leukemia. Proc Natl Acad Sci USA 2012; 109: 19397-19402.

6. Li Z, Cao Y, Jie Z, Liu Y, Li Y, Li J, Zhu G, Liu Z, Tu Y, Peng $G$, et al. miR-495 and miR-551a inhibit the migration and invasion of human gastric cancer cells by directly interacting with PRL-3. Cancer Lett 2012; 323: 41-47.

7. Nie S, Li K, Huang $Y, H u$ Q, Gao X, Jie S. miR-495 mediates metabolic shift in glioma cells via targeting Glut1. J Craniofac Surg 2015; 26: e155-158.

8. Wang L, Liu JL, Yu L, Liu XX, Wu HM, Lei FY, Wu S, Wang $X$. Downregulated miR-495 [corrected] inhibits the G1-S phase transition by targeting Bmi-1 in breast cancer. Medicine (Baltimore) 2015; 94: e718.

9. Clark AL, Naya FJ. MicroRNAs in the myocyte enhancer factor 2 (MEF2)-regulated Gt12-Dio3 noncoding RNA locus promote cardiomyocyte proliferation by targeting the transcriptional coactivator cited2. J Biol Chem 2015; 290: 23162-23172.

10. Jacobsen SE. Defining 'stemness': Notch and Wnt join forces? Nat Immunol 2005; 6: 234-236.

11. Kessler M, Hoffmann $K$, Brinkmann V, Thieck $O$, Jackisch $S$, Toelle B, Berger $H$, Mollenkopf HJ, Mangler $M$, Sehouli J, et al. The Notch and Wnt pathways regulate stemness and differentiation in human fallopian tube organoids. Nat Commun 2015; 6: 8989.

12. Lee TI, Johnstone SE, Young RA. Chromatin immunoprecipitation and microarray-based analysis of protein location. Nat Protoc 2006; 1: 729-748.

13. Li C, Xu N, Li YQ, Wang Y, Zhu ZT. Inhibition of SW620 human colon cancer cells by upregulating miRNA-145. World J Gastroenterol 2016; 22: 2771-2778.

14. Sha $D$, Lee $A M$, Shi $Q$, Alberts $S R$, Sargent $D J$, Sinicrope $F A$, Diasio RB. Association study of the let-7 miRNAcomplementary site variant in the $3^{\prime}$ untranslated region of the KRAS gene in stage III colon cancer (NCCTG N0147 clinical trial). Clin Cancer Res 2014; 20: 33193327.

15. Zhu R, Yang Y, Tian Y, Bai J, Zhang X, Li X, Peng Z, He $Y$, Chen $L$, Pan $Q$, et al. Ascl2 knockdown results in tumor growth arrest by miRNA-302b-related inhibition of colon cancer progenitor cells. PLOS One 2012; 7: e32170.

16. Ramalingam S, Subramaniam D, Anant S. Manipulating miRNA expression: a novel approach for colon cancer prevention and chemotherapy. Curr Pharmacol Rep 2015; 1: 141-153. 
17. Ahmed FE. miRNA as markers for the diagnostic screening of colon cancer. Expert Rev Anticancer Ther 2014; 14: 463-485.

18. Vassallo I, Zinn P, Lai M, Rajakannu P, Hamou MF, Hegi ME. WIF1 re-expression in glioblastoma inhibits migration through attenuation of non-canonical WNT signaling by downregulating the InCRNA MALAT1. Oncogene 2016; 35: 12-21.

19. Roperch JP, Incitti R, Forbin S, Bard F, Mansour H, Mesli F, Baumgaertner I, Brunetti F, Sobhani I. Aberrant methylation of NPY, PENK, and WIF1 as a promising marker for blood-based diagnosis of colorectal cancer. BMC Cancer 2013; 13: 566.

20. Zhang J, Tsoi H, Li X, Wang H, Gao J, Wang K, Go MY, Ng SC, Chan FK, Sung JJ, et al. Carbonic anhydrase IV inhibits colon cancer development by inhibiting the Wnt signalling pathway through targeting the WTAP-WT1TBL 1 axis. Gut 2016; 65: 1482-1493.

21. Qiu CZ, Wang MZ, Yu WS, Guo YT, Wang CX, Yang XF. Correlation of GOLPH3 gene with Wnt signaling pathway in human colon cancer cells. J Cancer 2016; 7: 928-934.

22. Liu C, Tu $Y$, Sun $X$, Jiang J, Jin $X$, Bo $X$, Li Z, Bian A, Wang $X$, Liu $D$, et al. Wnt/beta-catenin pathway in human glioma: expression pattern and clinical/prognostic correlations. Clin Exp Med 2011; 11: 105-112.

23. Reis M, Czupalla CJ, Ziegler N, Devraj K, Zinke J, Seidel $S$, Heck R, Thom S, Macas J, Bockamp E, et al. Endothelial Wnt/beta-catenin signaling inhibits glioma angiogenesis and normalizes tumor blood vessels by inducing PDGF-B expression. J Exp Med 2012; 209: 1611-1627.

24. Chen HL, Chew LJ, Packer RJ, Gallo V. Modulation of the Wnt/beta-catenin pathway in human oligodendroglioma cells by Sox 17 regulates proliferation and differentiation. Cancer Lett 2013; 335: 361-371.

25. Drescher U. A no-Wnt situation: SFRPs as axon guidance molecules. Nat Neurosci 2005; 8: 1281-1282.

26. Kafri $P$, Hasenson SE, Kanter I, Sheinberger J, Kinor N, Yunger S, Shav-Tal Y. Quantifying beta-catenin subcellular dynamics and cyclin D1 mRNA transcription during Wnt signaling in single living cells. Elife 2016; 5.

27. Liang L, Zhou W, Yang N, Yu J, Liu H. ET-1 promotes differentiation of periodontal ligament stem cells into osteoblasts through ETR, MAPK, and Wnt/beta-catenin signaling pathways under inflammatory microenvironment. Mediators Inflamm 2016; 2016: 8467849.

28. Zhang L, Xiong W, Xiong Y, Liu H, Li N, Du Y, Liu Y. Intracellular Wnt/beta-catenin signaling underlying 17beta-estradiol-induced matrix metalloproteinase 9 expression in human endometriosis. Biol Reprod 2016; 94: 70.

29. Cai T, Sun D, Duan Y, Wen P, Dai C, Yang J, He W. WNT/beta-catenin signaling promotes VSMCs to osteogenic transdifferentiation and calcification through directly modulating Runx2 gene expression. Exp Cell Res 2016; 345: 206-217. 